\title{
Model Statement for the Screening and Appointment of Academic Librarians Using a Search Commithee
}

\section{Follow these procedures for your next job opening}

n colleges, universities, and other institutions of higher education, the selection and appointment of librarians rank among the most important and consequential decisions to be made. To improve the decision-making process many library administrators use a consultative arrangement in the selection process. In some cases, the administrator chiefly responsible for the final decision simply requests comments and evaluations from the appropriate individuals. In others, this process is formalized by the establishment of a search committee. ${ }^{1}$ Consultation through a search committee solicits a breadth and range of opinion, and it facilitates objective consideration of the candidates' qualifications. It also promotes a sense of participation in the selection process by interested constituencies. Because selection is a two-way process, the benefits of using a search committee accrue to the candidates as well as to the institution. Candidates receive a clear and balanced view of the institution if they have the opportunity to be interviewed by several representatives of the institution. Search committees provide a forum for discussion, including an opportunity for the development of consensus among the interviewers and for the consideration of varied representative viewpoints.

The term "search committee" as used in this document designates a committee constituted for the purpose of performing any or all of the functions of compiling lists of candidates for vacant positions, screening (and eliminating) candidates in accord with agreed-upon selection criteria, and recommending the list of candidates to fill the position.

The following model is provided for those institutions that choose to use search committees. Institutions recruiting without search committees may also find these procedures useful.

\section{The role of the personnel officer}

If the institution is large enough to have a library personnel officer, that position would be responsible for administering the search for the search committee. Normally, the personnel officer sits on all search committees (either as a member or ex-officio).

\section{Formation of search committees}

Search committees may be elected or appointed. In either case, the immediate goal in the formation of such committees should be to create a body representative of the constituencies affected by the position. Persons accepting appointment to the committee automatically disqualify themselves as candidates for the position.

The administrator to whom the committee is responsible should instruct the committee in writing at the outset of the process as to the following:

A. The approximate date for submission of a list of nominees and proposed date of appointment;

B. The number of finalists to be recommended,

C. The affirmative action/equal opportunity requirements:

D. The arrangements for financial and staff resources; 
E. The responsibility for documenting committee actions and for preserving those records;

F. The need for confidentiality and discretion;

$\mathrm{G}$. The unique concerns with respect to the position.

A copy of the position description should accompany this information.

\section{Development and use of the position description or position announcement}

A written position description and a summary for advertising purposes should be prepared by the supervisor of the position at the outset of the search and should serve as the standard against which candidates' qualifications are judged. It should include a full account of the responsibilities and describe the educational background, experience, and competencies required or desired of the candidate. Qualifications should be written with equal opportunity and affirmative action considerations in mind.

\section{Posting the position}

The responsible administrator or the chairperson should file notification of the position with the local institution and in appropriate publications, taking care that all groups protected by equal opportunity/affirmative action legislation are made aware of the vacancy. Notifications should include a brief description of responsibilities, qualifications, salary, description of benefits, date position is available, application deadline, name of the person to whom applications should be submit ted, and a list of items to be submitted by the candidate.

\section{References}

A candidate's references are those individuals who the candidate lists to speak or write in support of his or her candidacy. References should be requested only for those candidates under active consideration. References should be solicited from individuals whose names are provided by the applicant, and the contents should be held in strict confidence by the committee. The names of references submitted by candidates should be limited to those individuals who can provide substantive information about the candidate's professional qualifications and should include, whenever possible, an administrator in the direct reporting line. Candidates are entitled to receive upon request a full list of those individuals from whom references have been solicited. Additional references may be solicited with the prior permission of the candidate. At the time of the request, referees should be advised whether or not the contents of the references will be made available to the candidate in accordance with local practice.

\section{Fair and uniform treatment}

All candidates, whether external or internal to the institution, should be accorded equal treatment in the screening and interview process. The search committee should be aware of institutional guidelines when developing questions to ask the candidate before the screening and interview process.

\section{Selection and interview procedures \\ A. Selection Process \\ Each committee should establish its own plan}

\section{The development of the statement}

In 1989 the ACRL Academic Stalus Commiltee (ASC) undertook a revision of the "Guidelines and Procedures for the Screening and Appointment of Academic librarians" document, first promulgated in 1977 (C\&RL News, September 1977: pp. 231-33). Committee members wished to render the language of the statement gender-neutral and to recognize the increasing use and importance of search committees in the recruitment of academic librarians. At the same time, the committee recognized that the search committee approach to hiring, although desirable, should not be binding upon the profession and that other approaches may be used. Because "model statement" implies that the approach is optional, rather than the more mandatory "guideline," the committee felt it to be the appropriate status.

The "Model Statement for the Screening and Appointment of Academic Librarians Using a Search Committee" is the result of the committee's efforts. Primary responsibility for the revision was assumed by ASC members Susan Kroll, Larry Wilt, and Larry R. Oberg, although all ASC members for the period 1989-1992 contributed to the revision. A draft of the revised document was reviewed by the Personnel Librarians' Discussion Group and the ACRL University Libraries Section. Suggestions from both groups were incorporated into the revision. The new model statement was approved by the ACRL Board at the 1992 summer conference in San Francisco.-Larry R. Oberg, chair, Academic Status Committee 
for screening and evaluating nominees and applicants consistent with library and institutionwide policies.

All applicants should be screened with reference to the qualifications and requirements stated in the position description. The purpose of initial screening is to identify and eliminate, early in the search process, nominees and applicants who are clearly unqualified. A letter should be sent to unqualified candidates stating that they will not be considered. The list of persons who remain under consideration after the initial screening should be those to whom the committee will be giving further consideration and from whom it will be seeking additional information. Fair, objective, consistent, and equitable processes should be used to narrow the field of candidates to the desired number of finalists, who will be invited for interviews.

\section{B. Interview Process}

Based on the candidate's and the institution's needs for information, the committee and the appropriate administrative officer shall determine the composition of the interview schedule. Before the interview, the candidates should be sent information about the library and its parent organization. Such information could include guides to the library, promotion and tenure guidelines, organization charts, and bylaws.

The interview schedule should be sent to the candidate several days before the interview occurs. Both the candidate and the interviewers should recognize the constraints of time during the interview process and should follow the schedule as closely as possible.

The cost of travel, meals, and lodging for candidates invited to the campus for interviews should be borne by the inviting institution. When this is not the practice, candidates should be so apprised when an invitation is issued. If an off-campus site is selected for the interview, the candidate's expenses should be paid by the inviting institution.

\section{Recommendation of candidates}

The committee should consider and evaluate in a timely manner the information gathered regarding the candidates in order to select a final list of candidates. The final list of candidates should be communicated by the chairperson to the administrator to whom the committee is responsible.

\section{IIGHI SQUEEZE?}

If your information needs are pushing your shelf space to its limits, turn to sociofile - the streamlined compact disc version of

\section{sociological abstracts} and Social Planning/Policy \& Development Abstracts.

sociofile offers you:

- High-quality abstracts and precise indexing of the worldwide serial literature of sociology and the related social sciences (including anthropology, education, demography, environmental studies, gender and race relat ons, penology and social policy) from more than 1,900 pri- mary sources, using SilverPlatler's state-of-the-art search and retrieval software.

The benefits of 24-hour, on-site search capability.

- The predictability of a fixed annual fee of $\$ 1,950$, single user, or $\$ 2,995$ LAN (up to 8 users), with no additional telecommunications charges.

\section{sociological abstracts, inc.}

p.o. box 22206 - san diego, ca $92192-0206$

(619) 695-8803 - FAX: (619) 695-0416 User Assistance: (800) 752-3945 
The First Source for Information on

\section{US BUSINESS \& TRADE}

WITH THE FORMER

SOVIET REPUBLICS

\section{Interflo}

A SOVIET TRADE

NEWS MONITOR

\section{COMPREHENSIVE ・ AUTHORITATIVE}

ISSN 0748 - 4631 FOUNDED IN 1981

FOR A KREE SAMPLE ISSUE OF INTERFLO

PLEASE CALL OR WRITE:

INTERFLO

P.O. BOX 42

MAPLEWOOD NJ 07040

(201) $763-9493$

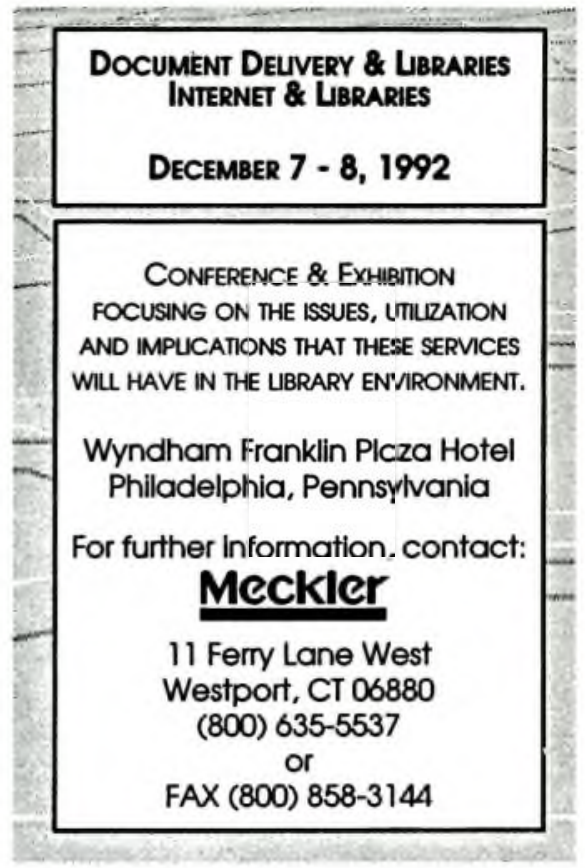

tive officer, the committee, or its designee should coordinate the announcement of the appointment with the successful candidate and should notify all other active candidates in writing.

\section{Reports, files, and records of proceedings}

The responsible administrator should instruct the chairperson of the committee as to what official reports are to be filed. The chairperson should complete the necessary reports promptly and accurately. The responsible administrator should discharge the committee and thank the members for their service. The files relating to the search should be stored or disposed of in accordance with laws, regulations, and practices currently applicable in the local setting.

\section{Notes}

${ }^{1}$ See "Model Statement of Criteria and Procedures for Appointment, Promotion in Academic Rank, and Tenure for College and University Librarians," CERL News (May 1987).

\section{${ }^{2}$ Ibid.}

Copies of the statement are available upon request from the $\mathrm{ACRL}$ office, $50 \mathrm{E}$. Huron St., Chicago, IL 60611-2795.
Upon receipt of the successful candidate's formal written acceptance, the chief administra- 